\title{
Rancang Bangun Sistem Penjadwalan Wawancara Mahasiswa Baru STMIK STIKOM Indonesia
}

\author{
Aniek Suryanti Kusuma ${ }^{1}$, I Gede Sujana Eka Putra ${ }^{2}$ \\ STMIK STIKOM Indonesia \\ 19anieksuryanti@yahoo.com,2gede_ekaputra@yahoo.com
}

\begin{abstract}
ABSTRAK. Sistem penjadwalan wawancara mahasiswa baru pada kampus STMIK STIKOM Indonesia saat ini dilaksanakan dengan melakukan pencatatan di buku besar. Kendala yang dihadapi adalah jadwal yang dibuat oleh bagian front office yang selaku bagian penerima mahasiswa baru tidak sesuai dengan shift kerja bagian konselor dan sering terjadi benturan dengan mahasiswa yang lain sehingga mengakibatkan mahasiswa menunggu lama. Hal ini akan mengakibatkan mahasiswa kecewa karena menganggap pelayanan di kampus tidak baik. Penelitian ini akan diawali dengan melakukan observasi terhadap sistem yang sudah ada kemudian dilanjutkan dengan requirement analysis dari pengguna sistem dan berikutnya dilakukan proses pengembangan. Dalam proses penjadwalan dalam pembuatan sistem ini menggunakan metode First In First Out. Tahap akhir dari penelitian ini adalah melakukan pengujian dengan menggunakan metode black box testing. Sistem penjadwalan wawancara mahasiswa baru ini dibangun dengan tujuan mengatur jadwal wawancara dari seluruh mahasiswa baru STMIK STIKOM Indonesia dengan baik sehingga mampu meningkatkan kualitas pelayanan kepada mahasiswa baru. Sistem ini diawali dengan penginputan data mahasiswa oleh bagian konselor, kemudian dilanjutkan dengan proses penjadwalan dan pengiriman email ke mahasiswa baru secara langsung. Jika jadwal telah terkirim maka mahasiswa baru akan melakukan wawancara sesuai dengan jadwal yang telah ditentukan dan bagian konselor bisa mencatat hasil wawancara pada sistem. Dengan adanya sistem ini diharapkan dapat meningkatkan kualitas pelayanan terhadap mahasiswa baru pada STMIK STIKOM Indonesia.
\end{abstract}

Kata Kunci: Black Box Testing, First In First Out, Penjadwalan

ABSTRACT. Scheduling interview system for prospective students in STMIK STIKOM Indonesia is currently carried out by manually recording it in a ledger. Some constraints faced are: the schedule made by Front Office as the admission is not in accordance to the Counselor's schedule and schedule clashes often occur between one student and another, so that students often have to queue for long time to do the counseling. This will cause disappointment for the students and they will consider that the Campus give bad service for the students. This research will be started with observing the existing system, then perform the Requirement Analysis from the system's user, and then do the development process. The Scheduling process in this system using First In First Out method. The final phase of this research is to do the testing using Blackbox method. This Prospective Students Interview Scheduling was built in order to have better arrangement for the interview schedule of all Prospective Students in STMIK STIKOM Indonesia, so as to improve the quality of service to new students. The system begins with the students data entry by the Counselor, then proceed with scheduling and email sending process to the students directly. When the schedule has been submitted, the Prospective Students will conduct the interview according to the schedule that has been arranged, and the Counselor can record the interview's results in the system. It is expected that STMIK STIKOM Indonesia can improve the quality of service for the Prospective Students.

Keywords: Blackbox Testing, First In First Out, Scheduling

\section{PENDAHULUAN}

\section{Latar Belakang}

Sebuah perusahaan tentunya memiliki banyak kegiatan dan agenda-agenda penting. Agar agenda-agenda penting tersebut dapat berjalan dengan baik maka dibutuhkan penjadwalan. Penjadwalan merupakan salah satu kegiatan penting dalam perusahaan. Penjadwalan adalah pengaturan waktu dari suatu kegiatan operasi, yang mencakup kegiatan mengalokasikan fasilitas, peralatan maupun tenaga kerja, dan menentukan urutan pelaksanaan bagi suatu kegiatan.

Salah satu kegiatan yang menggunakan prosedur penjadwalan pada kampus STMIK STIKOM Indonesia yang setiap semester membutuhkan jadwal untuk melakukan wawancara terhadap mahasiswa baru. Mahasiswa baru yang akan melakukan daftar ulang harus melakukan tes kemampuan dasar dan wawancara ke bagian konselor untuk mengetahui kemampuan dan bakat dari mahasiswa tersebut. Bagian Konselor kampus STMIK STIKOM Indonesia hanya satu orang, sedangkan pendaftaran mahasiswa dilakukan dari pagi hingga malam hari, bahkan hari libur juga 
bisa mendaftar. Hal ini akan sangat tidak mungkin dilakukan oleh satu orang konselor. Dengan demikian perlu dibuatkan jadwal wawancara untuk mahasiswa yang mendaftar ulang diluar jam kerja bagian konselor. Jadwal untuk sementara dibuatkan oleh Front Office dengan mencatat di buku besar. Kadang-kadang jadwal yang dibuat tidak sesuai dengan sift kerja bagian konselor dan sering terjadi benturan dengan mahasiswa yang lain sehingga mengakibatkan mahasiswa menunggu lama. Hal ini akan mengakibatkan mahasiswa kecewa karena menganggap pelayanan di kampus tidak baik.

Berdasarkan pemaparan tersebut, maka dipandang perlu merancang dan membangun sebuah aplikasi sistem penjadwalan wawancara untuk mahasiswa baru. Aplikasi penjadwalan tersebut akan membantu bagian konselor dalam melakukan penjadwalan dan mengolah data penjadwalan wawancara mahasiswa baru. Dengan tujuan untuk meminimalisir waktu proses, sehingga proses penjadwalan akan berjalan lebih efisien.

\section{Rumusan Masalah}

Rumusan masalah dalam penelitian ini adalah bagaimana rancang bangun sistem penjadwalan wawancara mahasiswa baru di STMIK STIKOM Indonesia untuk meningkatkan kualitas pelayanan?

\section{Tujuan Penelitian}

Untuk merancang bangun sebuah sistem yang mampu mengatur jadwal wawancara dari seluruh mahasiswa baru STMIK STIKOM Indonesia sehingga mampu meningkatkan kualitas pelayanan kepada mahasiswa baru.

\section{Manfaat Penelitian}

Dengan dilakukannya penelitian ini, diharapkan dapat memberikan manfaat bagi STMIK STIKOM Indonesia, diantaranya:

a. Membantu bagian konselor dalam melakukan penjadwalan tes wawancara calon mahasiswa baru.

b. Memudahkan bagian konselor dalam melakukan konfirmasi atau menghubungi calon mahasiswa baru mengenai waktu dan tempat tes wawancara yang telah ditentukan

\section{LANDASAN TEORI}

\section{Sistem}

Sistem merupakan kumpulan dari elemen-elemen yang berinteraksi untuk mencapai suatu tujuan tertentu. Menurut Jerry Fith Gerald, "sistem adalah suatu jaringan kerja dari prosedurprosedur yang saling berhubungan, berkumpul bersama-sama untuk melakukan suatu kegiatan atau menyelesaikan suatu sasaran tertentu" (Jogiyanto, 2005).

\section{Sistem Informasi}

Menurut Sistem informasi adalah suatu sistem di dalam suatu organisasi yang mempertemukan kebutuhan pengelolaan transaksi harian, mendukung operasi, bersifat manajerial, dan kegiatan strategi dari suatu organisasi dan menyediakan pihak luar tertentu dengan laporanlaporan yang dibutuhkan (Hutahaean, 2014), Sistem Informasi terdiri dari komponen-komponen yang disebut dengan istilah blok bangunan, yaitu diantaranya sebagai berikut.

a. Blok masukan (input block)

Input mewakili data yang masuk ke dalam sistem informasi input di sini termasuk metode metode dan media yang digunakan untuk menangkap data yang akan dimasukkan, yang dapat berupa dokumen dasar. 
b. Blok model (model block)

Blok ini terdiri dari kombinasi prosedur, logika, dan metode matematik yang akan memanipulasi data input, dan data yang tersimpan di basis data dengan cara yang sudah tertentu untuk menghasilkan keluaran yang sudah diinginkan.

c. Blok keluaran (output block)

Produk dari sistem informasi adalah keluaran yang merupakan informasi yang berkualitas dan dokumentasi yang berguna untuk semua tingkatan manajemen serta semua pemakai sistem.

d. Blok teknologi (technology block)

Teknologi digunakan untuk menerima input, menjalankan model menyimpan dan mengakses data menghasilkan dan mengirimkan Keluaran dan membantu pengendalian diri secara keseluruhan

e. Blok basis (database block)

Merupakan kumpulan dari data yang saling berhubungan satu dengan yang lainnya, tersimpan di perangkat keras komputer dan digunakan perangkat lunak untuk memanipulasinya.

f. Blok kendali (control block)

Banyak faktor yang dapat merusak sistem informasi misalnya bencana alam, api temperatur tinggi, air, debu, kecurangan-kecurangan, kejanggalan sistem itu sendiri, kesalahan-kesalahan, ketidakefisienan, sabotase, dan segalanya. Pengendalian perlu dirancang dan diterapkan untuk meyakinkan bahwa hal-hal yang dapat merusak sistem dapat dicegah atau bila terlanjur terjadi kesalahan dapat langsung diatasi.

\section{Penjadwalan}

Penjadwalan (scheduling) merupakan salah satu kegiatan penting dalam perusahaan. Penjadwalan adalah suatu kegiatan operasi, yang mencakup kegiatan mengalokasikan fasilitas, peralatan maupun tenaga kerja, dan menentukan urutan pelaksanaan bagi suatu kegiatan operasi (Herjanto,2007),.

Penjadwalan bertujuan meminimalkan waktu proses, waktu tunggu langganan, dan tingkat persediaan, serta penggunaan yang efisien dari fasilitas, tenaga kerja, dan peralatan. Penjualan biasanya disusun dengan mempertimbangkan berbagai keterbatasan yang ada. Terlepas dari jenis perusahaannya, setiap perusahaan perlu untuk melakukan penjadwalan sebaik mungkin agar dapat memperoleh utilitasi yang maksimum dari sumber daya produksi dan aset lain yang dimilikinya. Penjadwalan yang baik akan memberikan dampak positif yaitu rendahnya biaya operasi.

\section{FIFO (First In First Out)}

FIFO merupakan penjadwalan yang tidak berprioritas dan penjadwalan paling sederhana (Haryanto, 2012).Berikut adalah karakteristik FIFO.

a. Proses diberi jatah waktu oleh pemroses berdasarkan waktu kedatangan.

b. Proses dijalankan sampai selesai saat sudah mendapat jatah waktu dari pemroses.

Penjadwalan ini mempunyai karakter sebagai berikut.

a. Baik untuk sistem batch yang sangat jarang berinteraksi dengan pemakai.

b. Contoh: aplikasi analisis numerik maupun pembuatan tabel.

c. Sangat tidak baik tidak berguna untuk sistem interaktif, karena tidak memberi waktu tanggap yang baik.

d. Tidak dapat digunakan untuk sistem waktu nyata Real Time application.

FIFO memiliki algoritma yang sederhana. Prinsip dari algoritma FIFO adalah seperti antrian. Halaman yang masuk lebih dulu maka akan keluar lebih dulu juga. Algoritma ini menggunakan struktur data stack. Apabila tidak ada frame kosong saat terjadi page fault maka korban yang akan dipilih adalah frame yang berada di stack paling bawah yaitu halaman yang berada paling lama berada di memori. dengan hanya informasi mengenai lama berada di memori maka algoritma ini dapat memindahkan file yang sering digunakan (Haryanto,2012). 


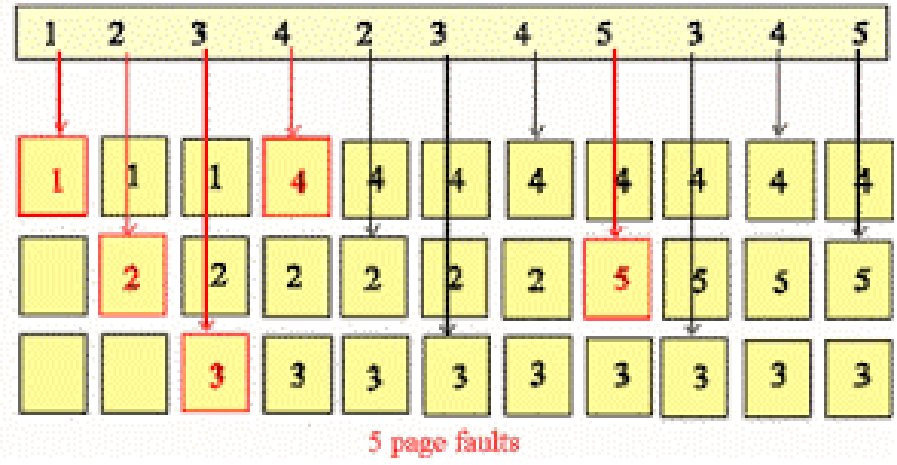

Gambar 1. Algoritma FIFO

\section{System Development Life Cycle (SDLC)}

SDLC merupakan proses mengembangkan atau mengubah suatu sistem perangkat lunak dengan menggunakan model-model dan metodologi yang digunakan orang untuk mengembangkan sistemsistem perangkat lunak sebelumnya (berdasarkan best practice atau cara-cara yang sudah teruji baik). Tahapan-tahapan yang ada pada SDLC secara global adalah sebagai berikut : inisiasi (initiation), pengembangan konsep sistem (system concept development), perencanaan (planning), analisis kebutuhan (requirements analysis), desain (design), pengembangan (development), integrasi dan pengujian (integration and test), implementasi (implementation), operasi dan pemeliharaan (operations and maintenance), dan disposisi (disposition).

SDLC memiliki beberapa model dalam penerapan tahapan prosesnya, salah satunya adalah model waterfall. Model ini menyediakan pendekatan alur hidup perangkat lunak secara sekuensial atau terurut dimulai dari analisis, desain, pengodean, pengujian, dan tahap pendukung (support). Gambar 2 berikut adalah ilustrasi model waterfall.

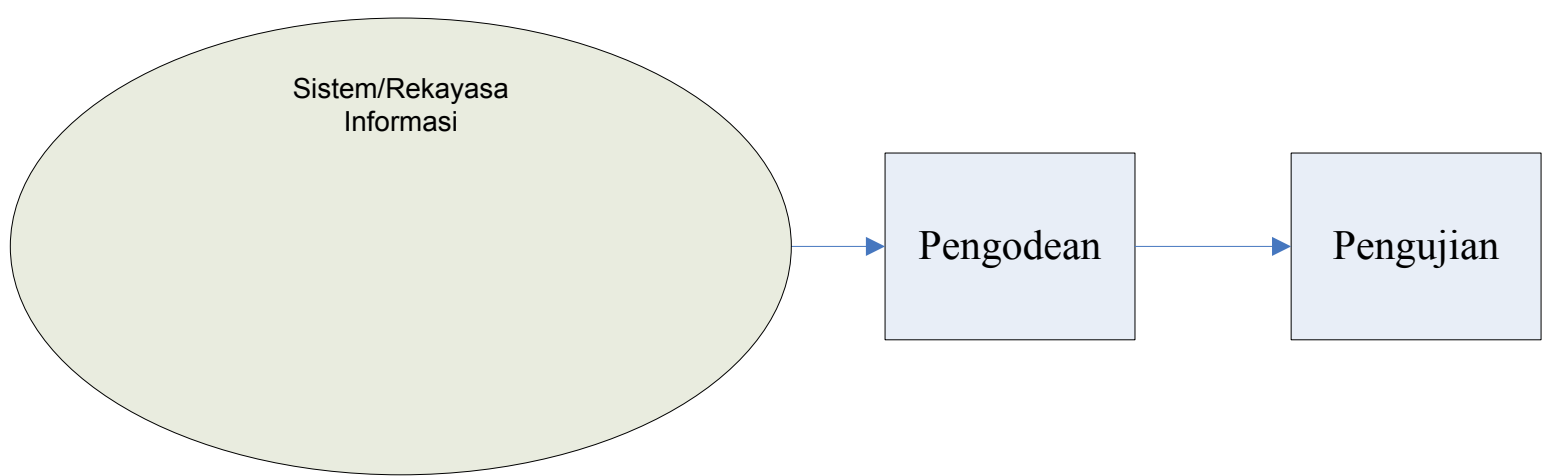

Gambar 2. Ilustrasi Model Waterfall

\section{Data Flow Diagram}

DFD adalah suatu model logika data atau proses yang dibuat untuk menggambarkan asal data dan tujuan data yang keluar dari sistem, tempat penyimpanan data, proses apa yang menghasilkan data tersebut serta interaksi antara data yang tersimpan dan proses yang dikenakan pada data tersebut (Kusrini, 2007).

Ada dua jenis DFD, yaitu DFD logis dan DFD fisik. DFD logis menggambarkan proses tanpa menyarankan bagaimana mereka akan melakukan, sedangkan DFD fisik menggambarkan proses model berikut implementasi pemrosesan informasinya (Al Fatta, 2007). Ada beberapa metode untuk menggambarkan elemen-elemen tersebut yang dapat dilihat pada Tabel 1. 
Tabel 1. Simbol Data Flow Diagram

\begin{tabular}{|l|l|l|}
\hline Gane dan Sarson & Yourdon dan DeMarco & \multicolumn{1}{|c|}{ Keterangan } \\
\hline & & $\begin{array}{l}\text { External Entity merupakan entitas di } \\
\text { lingkungan luar sistem yang dapat } \\
\text { berupa orang, organisasi atau sistem lain } \\
\text { yang berada di lingkungan luar yang } \\
\text { akan memberikan input atau menerima } \\
\text { output dari system }\end{array}$ \\
\hline & $\begin{array}{l}\text { Arus Data yang menunjukkan arus dari } \\
\text { data yang dapat berupa masukan untuk } \\
\text { sistem atau hasil dari proses sistem. }\end{array}$ \\
\hline & $\begin{array}{l}\text { Proses adalah kegiatan atau kerja yang } \\
\text { dilakukan oleh orang, mesin, atau } \\
\text { komputer. }\end{array}$ \\
\hline
\end{tabular}

\section{Entity Relationship Diagram}

ERD adalah gambar atau diagram yang menunjukkan informasi dibuat, disimpan dan digunakan dalam sistem bisnis (Al Fatta, 2007). Entitas biasanya menggambarkan jenis informasi yang sama. Elemen-elemen yang ada pada ERD ditampilkan pada Tabel 2 berikut.

Tabel 2. Simbol Entity Relationship Diagram

\begin{tabular}{|c|c|}
\hline Simbol & Keterangan \\
\hline Entitas & $\begin{array}{l}\text { Entity merupakan suatu objek atau konsep } \\
\text { mengenai tempat yang anda inginkan untuk } \\
\text { menyimpan }\end{array}$ \\
\hline & $\begin{array}{l}\text { Relationships mengilustrasikan bagaimana dua } \\
\text { entitas berbagi informasi di dalam struktur basis } \\
\text { data. }\end{array}$ \\
\hline Atribut & $\begin{array}{l}\text { Attributes adalah sifat-sifat atau karakteristik dari } \\
\text { suatu entitas }\end{array}$ \\
\hline & $\begin{array}{l}\text { Penghubung antara relasi dan entitas di mana di } \\
\text { kedua ujungnya memiliki multiplicity kemungkinan } \\
\text { jumlah pemakaian }\end{array}$ \\
\hline
\end{tabular}

\section{Pemrograman Berbasis Web}

Internet adalah kelompok atau kumpulan dari jutaan komputer. Penggunaan Internet memungkinkan kita untuk mendapatkan informasi dari komputer yang ada dalam kelompok tersebut dengan asumsi bahwa pemilik komputer memberikan ijin akses. Untuk mendapatkan sejumlah informasi, sekumpulan protokol harus digunakan, yaitu sekumpulan aturan yang menetapkan bagaimana suatu informasi dapat dikirim dan diterima.

Salah satu unsur yang paling umum digunakan dari Internet selain e-mail adalah World Wide Web. Dewasa ini, WWW atau yang sering juga disebut sebagai "Web" saja merupakan aplikasi Internet yang paling popular. Karena Web begitu popular, banyak orang kemudian salah mengidentikkannya dengan Internet (Simarmata, 2006).

Ada dua komponen dasar di dalam arsitektur Web, yaitu browser Web dan server Web. Browser Web menawarkan antarmuka grafis untuk pengguna dan bertanggung jawab untuk 
komunikasi dengan server Web. Protokol komunikasi antara browser dan server Web mengikuti protocol HTTP yang distandarisasi.

\section{Bahasa Pemrograman PHP}

PHP merupakan script yang menyatu dengan HTML dan berada pada server (server side HTML embedded scripting). Dengan PHP ini Anda dapat membuat beragam aplikasi berbasis web, mulai dari halaman web yang sederhana sampai aplikasi komplek yang membutuhkan koneksi ke database. PHP adalah bahasa pemrograman script yang paling banyak dipakai saat ini. PHP banyak dipakai untuk memprogram situs web dinamis, walaupun tidak tertutup kemungkinan digunakan untuk pemakaian lain.

Adapun kelebihan dari bahasa pemrograman PHP adalah sebuah bahasa script yang tidak melakukan sebuah kompilasi dalam penggunaanya. Web Server yang mendukung PHP dapat ditemukan dimana - mana dari mulai Apache, IIS, Lighttpd, hingga Xitami dengan konfigurasi yang relatif mudah. Dalam sisi pengembangan lebih mudah, karena banyaknya milis - milis dan developer yang siap membantu dalam pengembangan.

\section{MySQL}

MySQL adalah sebuah program database server yang mampu menerima dan mengirimkan datanya dengan sangat cepat, multi user serta menggunakan perintah standar SQL (Structured Query Language). MySQL merupakan sebuah database server yang free artinya kita bebas menggunakan database ini untuk keperluan pribadi atau usaha tanpa harus membeli atau membayar lisensinya. MySQL pertama kali dirintis oleh seorang programmer database bernama Michael Widenuius. MySQL juga merupakan program yang dapat mengakses suatu database MySQL yang berposisi sebagai client. Database MySQL merupakan suatu perangkat lunak database yang berbentuk database relasional atau dalam bahasa basis data sering kita sebut dengan Relational Database Management System (RDBMS) yang menggunakan suatu bahasa permintaan bernama SQL.

\section{Pengujian Perangkat Lunak}

Pengujian yang akan dilakukan pada penelitian ini adalah pengujian Black Box. Pengujian black box berfokus pada persyaratan fungsional perangkat lunak. Pengujian black box berusaha menemukan kesalahan dalam kategori: fungsi-fungsi yang tidak benar atau hilang, kesalahan interface, kesalahan dalam struktur data atau akses database eksternal, kesalahan kinerja, dan inisialisasi kesalahan terminasi (Pressman, 2002). Adapun pedoman pengujian pada metode black box adalah pengujian Graphical User Interfaces (GUI), pengujian arsitektur client/server, pengujian dokumentasi dan fasilitas help, pengujian sistem real-time.

\section{METODE PENELITIAN}

\section{Alur Analisis}

Dalam melakukan penelitian ini, menggunakan tahapan-tahapan pengembangan sistem yang ditunjukkan pada Gambar 3.
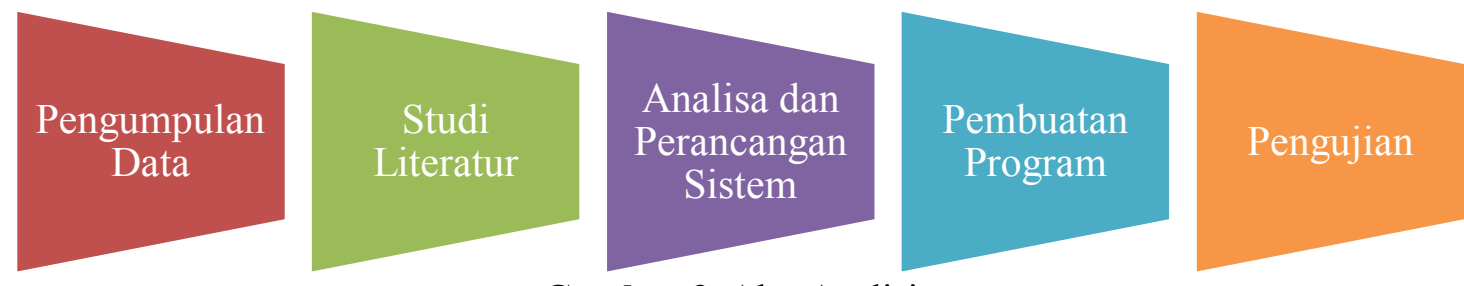

Gambar 3. Alur Analisis 


\section{Teknik Pengumpulan Data}

\section{a. Studi Literatur}

Studi literatur merupakan metode pengumpulan data dan informasi yang diperoleh melalui sumber-sumber seperti buku, karya tulis, dan sumber lain yang berhubungan dengan objek penelitian terutama mengenai perancangan sistem informasi dan blackbox testing sehingga dapat membantu dalam proses perancangan sistem penjadwalan wawancara yang akan dibuat.

\section{b. Observasi}

Observasi merupakan metode pengumpulan data dan informasi yang diperoleh dengan cara melakukan pengamatan langsung terhadap objek penelitian seperti aktivitas front office menerima pendaftaran wawancara dan bagian konselor dalam melakukan wawancara terhadap mahasiswa baru.

\section{c. Wawancara}

Wawancara dilakukan terhadap bagian konselor dan front office dalam menangani penjadwalan wawancara terhadap mahasiswa baru serta menentukan kebutuhan pengguna terhadap sistem yang akan dibangun nanti.

\section{Gambaran Umum Sistem}

Sistem penjadwalan yang terjadi selama ini di kampus STMIK STIKOM Indonesia dapat dikatakan masih sangat manual. Mahasiswa baru untuk diwawancara oleh bagian konselor sementara dibuatkan oleh Front Office dengan mencatat di buku besar. Kadang-kadang jadwal yang dibuat tidak sesuai dengan sift kerja bagian konselor dan sering terjadi benturan dengan mahasiswa yang lain sehingga mengakibatkan mahasiswa menunggu lama. Hasil wawancara dicatat pada sebuah buku sehingga dalam pencarian hasil catatan mahasiswa baru cukup lama.

\section{HASIL DAN PEMBAHASAN}

\section{Analisis Sistem}

\section{a. Kebutuhan Fungsional}

Sistem harus dapat melakukan penjadwalan wawancara seperti menambahkan, mengubah, menghapus data jadwal dan menyimpan ke dalam database jadwal.

Pada sistem penjadwalan ini beberapa hal lainnya yang harus mampu dilakukan adalah

1. User dapat menambahkan data mahasiswa

2. User dengan Hak Akses Admin dapat mengelola data konselor dan administrator..

3. User dengan Hak Akses konselordapat menentukan jadwal wawancara dan mencatat hasil wawancara.

\section{b. Kebutuhan Non Fungsional}

\section{Operasional}

a. Sistem dapat digunakan pada sistem operasi Microsoft Windows XP, Microsoft Windows 7, Microsoft Windows 8, Microsoft Windows 10, Linux, Centos.

b. Spesifikasi komputer minimum adalah Pentium IV keatas.

c. Kebutuhan memory Ram minimal 1Gigabyte.

d. Dijalankan menggunakan media Web Browser.

\section{Keamanan}

Dilengkapi dengan username dan password untuk masuk sistem dengan hak akses yang berbeda untuk atasan dan staff dalam mengakses sistem.

\section{Analisis Masalah dan Kebutuhan Sistem}

Analisa dan solusi yang bisa ditawarkan dari permasalahan yang terjadi pada sistem penjadwalan waawancara mahasiswa baru dapat dilihat pada table 3 . 
Tabel 3. Analisa Masalah Dan Kebutuhan Sistem

\begin{tabular}{|c|c|c|}
\hline Masalah & Sasaran & Solusi \\
\hline $\begin{array}{l}\text { Susahnya mencari data } \\
\text { mahasiswa baru yang akan } \\
\text { diwawancara }\end{array}$ & $\begin{array}{lr}\text { Memudahkan } & \text { konselor } \\
\text { dalam } & \text { melakukan } \\
\text { pencarian } & \text { data } \\
\text { mahasiswa } & \\
\end{array}$ & $\begin{array}{l}\text { Pembuatan form pencatatan atau } \\
\text { fasilitas import data mahasiswa baru } \\
\text { beserta fitur pencarian }\end{array}$ \\
\hline $\begin{array}{l}\text { Jadwal sering bentrok dan } \\
\text { tidak sesuai sift kerja } \\
\text { konselor }\end{array}$ & $\begin{array}{lrr}\text { Jadwal tidak } & \text { pernah } \\
\text { bentrok dan } & \text { sesuai } \\
\text { dengan sift kerja konselor }\end{array}$ & $\begin{array}{l}\text { Pembuatan form jadwal yang bisa } \\
\text { diatur sendiri oleh konselor atau } \\
\text { otomatis. Setelah jadwal selesai } \\
\text { sistem bisa mengirim email ke } \\
\text { mahasiswa baru untuk } \\
\text { menginformasikan jadwal wawancara. }\end{array}$ \\
\hline $\begin{array}{l}\text { Catatan hasil wawancara } \\
\text { dicatat di dalam buku, } \\
\text { sehingga saat dibutuhkan } \\
\text { untuk mengetahui hasil } \\
\text { wawancara mahasiswa } \\
\text { tertenturanan } \\
\text { membutuhkan waktu yang } \\
\text { sangat lama }\end{array}$ & $\begin{array}{l}\text { Hasil catatan tersimpan } \\
\text { dengan baik dan saat } \\
\text { dibutuhkan dapat dengan } \\
\text { cepat kita dapatkan }\end{array}$ & $\begin{array}{l}\text { Adanya form pencatatan hasil } \\
\text { wawancara dan fitur pencarian hasil } \\
\text { wawancara }\end{array}$ \\
\hline
\end{tabular}

\section{Gambaran Sistem yang Diusulkan}

Proses wawancara mahasiswa di kampus STMIK STIKOM Indonesia dilakukan oleh bagian konselor. Untuk mengatur jadwal mahasiswa diwawancara maka bagian konselor harus memasukkan data mahasiswa baru ke dalam sistem terlebih dahulu. Penjadwalan bisa dilakukan dengan membuat kelompok kelas berdasarkan jurusan. Sistem dapat langsung menentukan jadwal wawancara secara otomatis ataupun secara manual sesuai dengan kebutuhan bagian konselor. Setelah jadwal terbentuk, maka bagian konselor mengirim email dengan cukup menekan tombol email pada sistem. Hasil wawancara terhadap mahasiswa baru dapat disimpan pada sistem dan memberikan status bahwa mahasiswa tersebut telah diwawancara.

\section{Event List}

Dalam pembuatan sistem terdapat beberapa langkah atau prosedur kerja yang ada, dimana langkah atau pembagian sistem dapat di lihat dalam struktur event list di bawah ini:

1. Data Login

2. Data kelompok wawancara

2.1 Tambah Data Kelompok Wawancara

2.2 Ubah Data Kelompok Wawancara

2.3 Hapus Data Kelompok Wawancara

2.4 Cetak Data Kelompok Wawancara

3. Data mahasiswa

3.1 Tambah Mahasiswa

3.2 Ubah Mahasiswa

3.3 Cari Mahasiswa

3.4 Cetak Mahasiswa

4. Wawancara
1.1 Simpan Kehadiran
1.2 Pembatalan kehadiran
1.3 Tambah Catatan
1.4 Ubah Catatan
1.5 Cari Catatan 
5. Statistik

5.1 Tampil data Statistic

5.2 Cetak data Statistik

6. Data Konselor

6.1 Tambah Konselor

6.2 Ubah Konselor

7. Data Administrator

7.1 Tambah Administrator

7.2 Ubah Administrator

\section{Konteks Diagram}

Pada gambar 4 merupakan konteks diagram sistem penjadwalan mahasiswa baru pada STMIK STIKOM Indonesia.

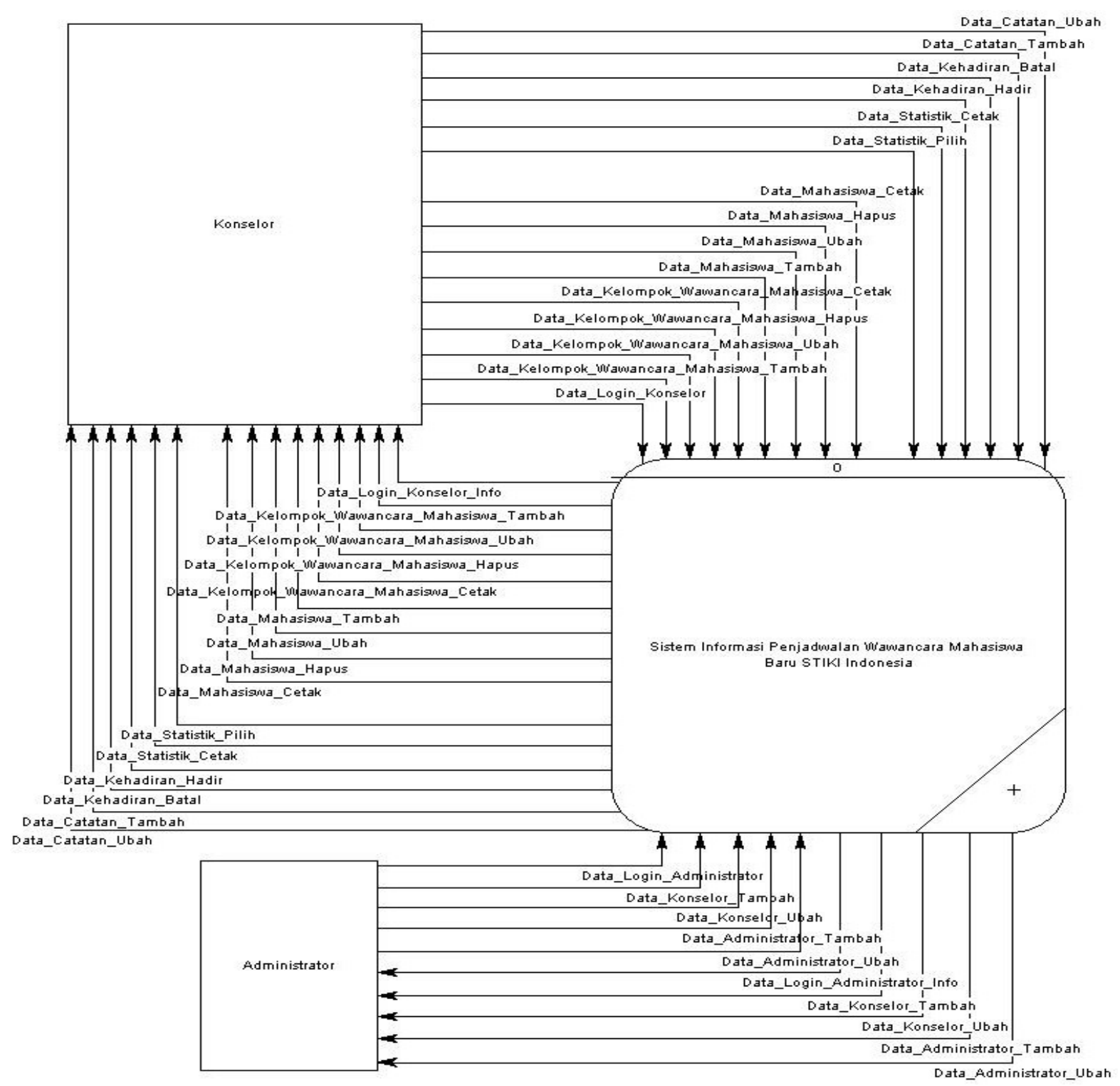

Gambar 4. Context Diagram 


\section{Data Flow Diagram}

Data Flow Diagram level 0 ini menunjukkan proses-proses utama yang terjadi di dalam sistem penjadwalan mahasiswa baru pada STMIK STIKOM Indonesia yang sedang di bangun.

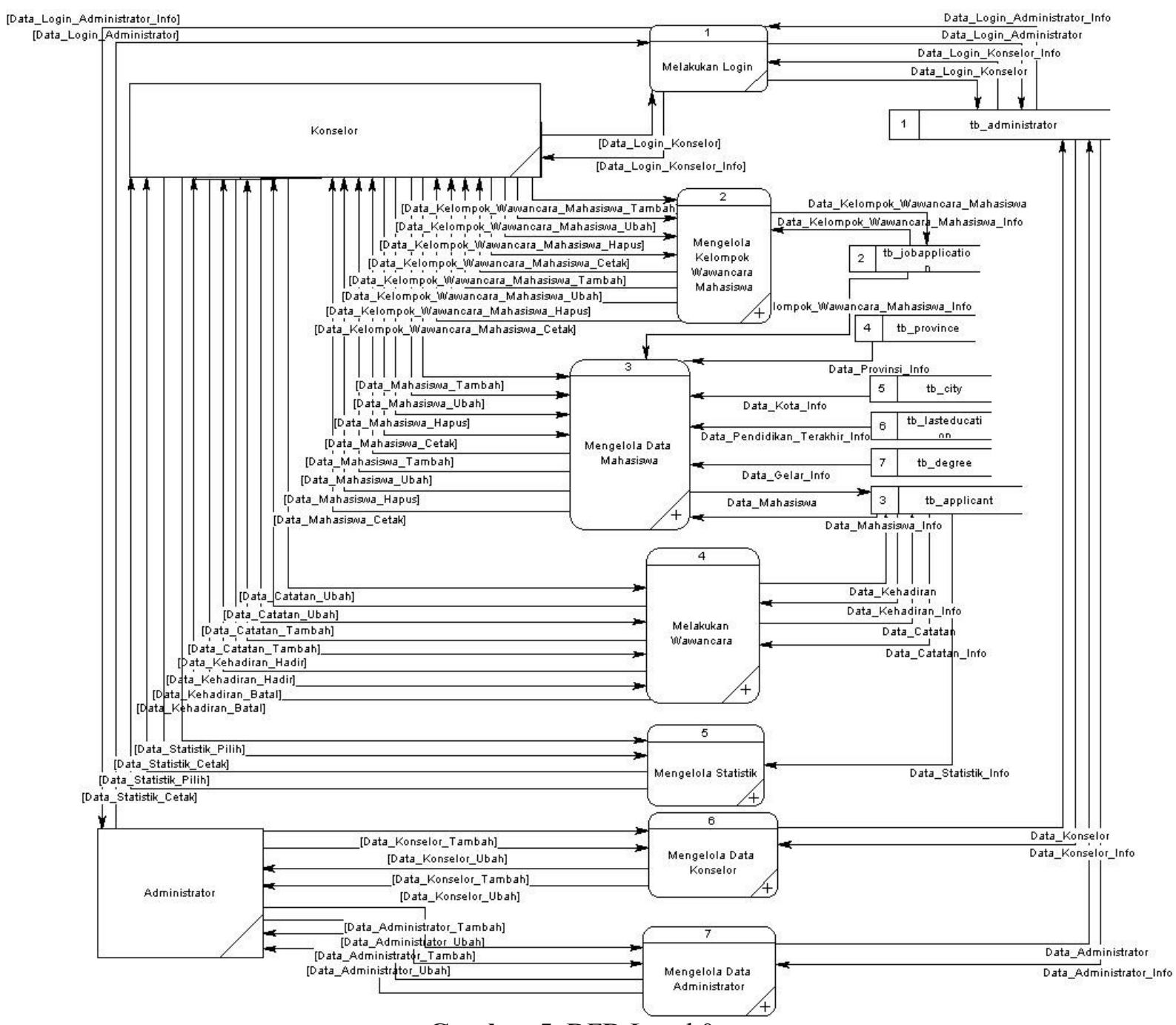

Gambar 5. DFD Level 0

Pada gambar 5 DFD Level 0 digambarkan secara garis besar bahwa untuk menjalankan sistem ini pada awalnya semua user Admin dan konselor akan melakukan login terlebih. Setelah login selanjutnya sistem akan mengecek user akses dari masing-masing user dan kemudian masuk ke halaman Home. Untuk user admin mampu mengelola data konselor dan data administrator sedangkan user konselor mampu mengelola kelompok wawancara, data mahasiswa, mencatat wawancara, dan mengelola statistik.

\section{Entity Relationship Diagram}

Gambar 6 menunjukkan struktur relasi antar tabel dalam pembuatan sistem penjadwalan wawancara mahasiswa. Disini terdapat tujuh tabel yaitu tabel mahasiswa, pendidikan terakhir, gelar, provinsi, kota, kelompok wawancara dan administrator. 


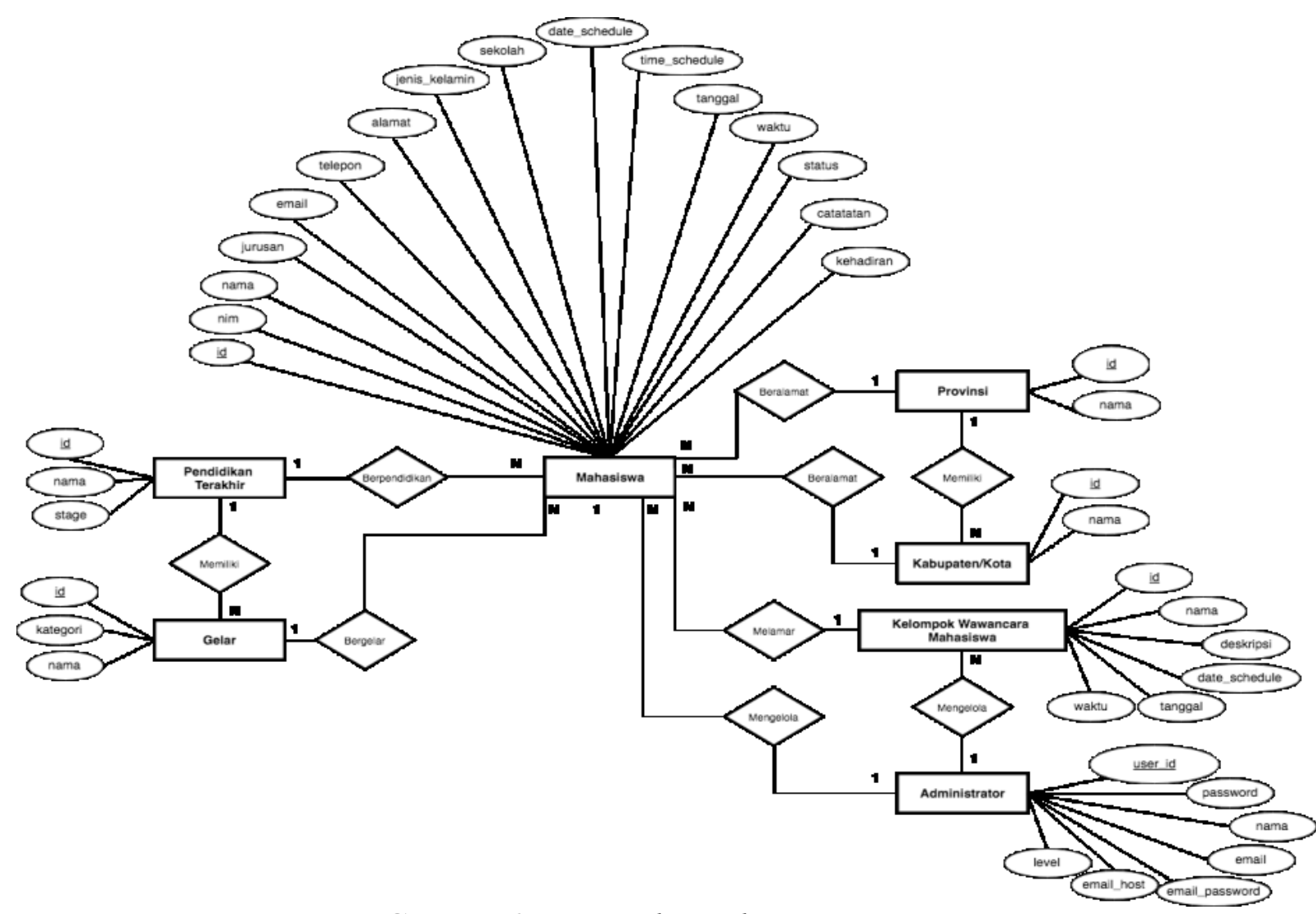

Gambar 6. Entity Relationship Diagram

\section{Implementasi Sistem}

\section{A. Implementasi Antarmuka}

\section{Halaman Login}

Gambar 7 yaitu halaman login, halaman login ini merupakan halaman yang menampilkan form untuk administrator yaitu admin untuk masuk ke dalam sistem agar dapat mengelola datadata yang terdapat pada database dan konselor untuk mengatur jadwal wawancara.

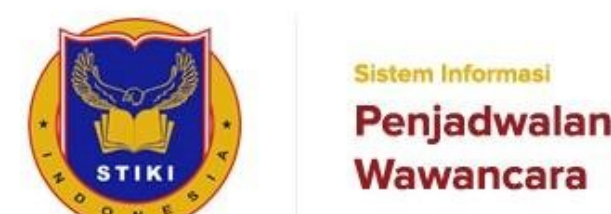

Gambar 7. Halaman Login 


\section{Halaman Home}

Gambar 8 dapat dijelaskan halaman Home yaitu halaman yang pertama kali tampil saat user berhasil login. Pada halaman ini terdapat logo dan menu navigasi yaitu Data Kelompok Wawancara, Data Mahasiswa, Penjadwalan dan Undangan, Statistik, dan Logout

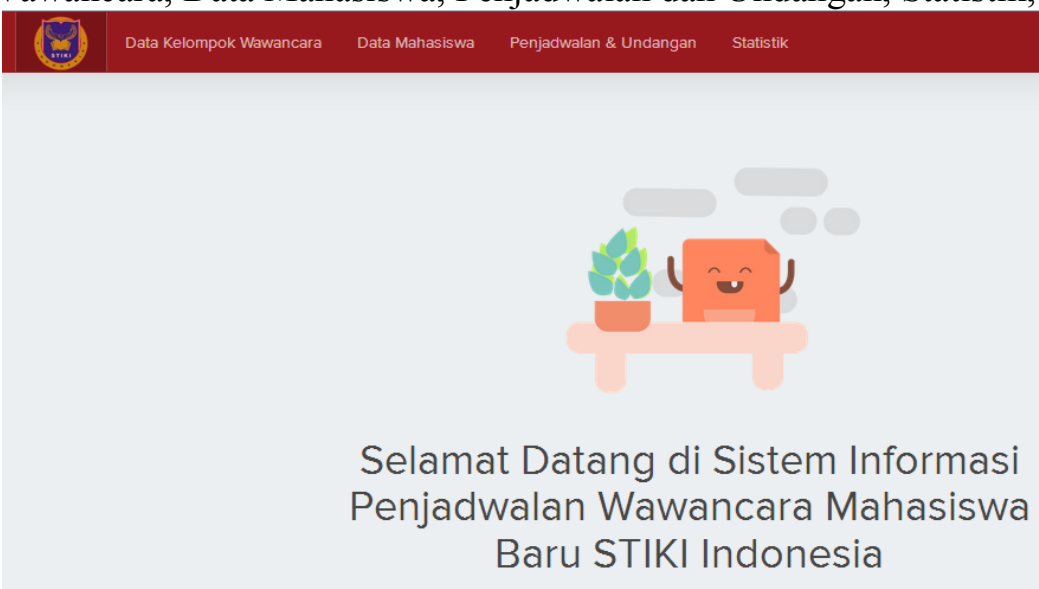

Gambar 8. Halaman Home

\section{Halaman Data Mahasiswa}

Pada Gambar 9 halaman Data Mahasiswa digunakan untuk menambah data mahasiswa baru yang akan diwawancara. Form ini terdapat tombol input data, import Excel dan pencarian.

\begin{tabular}{|c|c|c|c|c|c|c|c|c|}
\hline & (1). & Data Kelompok Wc & lawancara & Data Mahasiswa & \& Undangan & & & Logout \\
\hline \multicolumn{3}{|c|}{ Data Mahasiswa } & + Input Data & 园 Import Excel & Manajemen Teknik Informatika (MTI). $\mathbf{x}$ & \multicolumn{2}{|c|}{ Cari disini... } & $\theta$ \\
\hline No & NIM & Nama & Jurusan & Info Kontak & Alamat & Js.Kel & Kelompok Wawancara & Pilihan \\
\hline 1 & 17101498 & $\frac{\text { I Putu Mahesa }}{\text { Kama Artha }}$ & & $\begin{array}{l}\text { mahesakamaartha@gmail.com } \\
08170670571\end{array}$ & $\begin{array}{l}\text { Jalan Hayam Wuruk Gang XVII No. 2C, Kota } \\
\text { Denpasar - Bali }\end{array}$ & L & $\begin{array}{l}\text { Manajemen Teknik Informatika } \\
\text { (MTI) - } 2017 \text { - Pagi [kode: 19] }\end{array}$ & $\checkmark$ \\
\hline 2 & 17101498 & $\begin{array}{l}\text { I Putu Prati } \\
\text { Natha }\end{array}$ & & $\begin{array}{l}\text { pratinatha@gmail.com } \\
087762103811\end{array}$ & $\begin{array}{l}\text { JI. Pakis Aji Gg. Cengana Sari V, Kota } \\
\text { Denpasar - Bali }\end{array}$ & L & $\begin{array}{l}\text { Manajemen Teknik Informatika } \\
\text { (MTI) - } 2017 \text { - Pagi [kode: 19] }\end{array}$ & . \\
\hline 3 & 17101498 & Wahyu Astika & & $\begin{array}{l}\text { wahyuastika@gmail.com } \\
085737213141\end{array}$ & Jalan Cempaka, Kabupaten Tabanan - Bali & L & $\begin{array}{l}\text { Manajemen Teknik Informatika } \\
\text { (MTI) - } 2017 \text { - Pagi [kode: 19] }\end{array}$ & . \\
\hline 4 & 17101498 & $\frac{\text { Komang Mei }}{\text { Antara }}$ & & $\begin{array}{l}\text { komangmeiantara@gmail.com } \\
085738491182\end{array}$ & $\begin{array}{l}\text { JI. Siulan Gang Nusa Indah No. } 19 \text { - Penatih, } \\
\text { Denpasar, Bali, Kota Denpasar - Bali }\end{array}$ & L & $\begin{array}{l}\text { Manajemen Teknik Informatika } \\
\text { (MTI) - } 2017 \text { - Pagi [kode: 19] }\end{array}$ & . \\
\hline 5 & 17101498 & Putu Sastrawan & & $\begin{array}{l}\text { one.putu@gmail.com } \\
081805336696\end{array}$ & $\begin{array}{l}\text { Jalan Sulatri Gang } 3 \text { No. 7, Kota Denpasar - } \\
\text { Bali }\end{array}$ & L & $\begin{array}{l}\text { Manajemen Teknik Informatika } \\
\text { (MTI) - } 2017 \text { - Pagi [kode: 19] }\end{array}$ & . \\
\hline 6 & 17101498 & $\begin{array}{l}\text { I Wayan Artha } \\
\text { Suantara }\end{array}$ & & $\begin{array}{l}\text { arthasuantara93@gmail.com } \\
081339343109\end{array}$ & $\begin{array}{l}\text { Selat Bawak, Marga, Kabupaten Tabanan - } \\
\text { Bali }\end{array}$ & L & $\begin{array}{l}\text { Manajemen Teknik Informatika } \\
\text { (MTI) - } 2017 \text { - Pagi [kode: 19] }\end{array}$ & . \\
\hline 7 & 17101498 & $\frac{\text { I Made }}{\underline{\text { Sudahrma Putra }}}$ & & $\begin{array}{l}\text { mysudarma@gmail.com } \\
087860916915\end{array}$ & Mengwi Tani, Kabupaten Badung - Bali & L & $\begin{array}{l}\text { Manajemen Teknik Informatika } \\
\text { (MTI) - } 2017 \text { - Pagi [kode: } 19 \text { ] }\end{array}$ & . \\
\hline
\end{tabular}

Gambar 9. Halaman Data Mahasiswa

Tombol Import data digunakan jika data mahasiswa sudah tersedia dalam bentuk file excel. Sedangkan bagian konselor ingin menginputkan data mahasiswa dari sistem dapat dilakukan dengan menekan tombol Input Data. Input data dapat dilakukan dengan mengisi form tambah data mahasiswa yang dapat dilihat pada gambar 10 . 


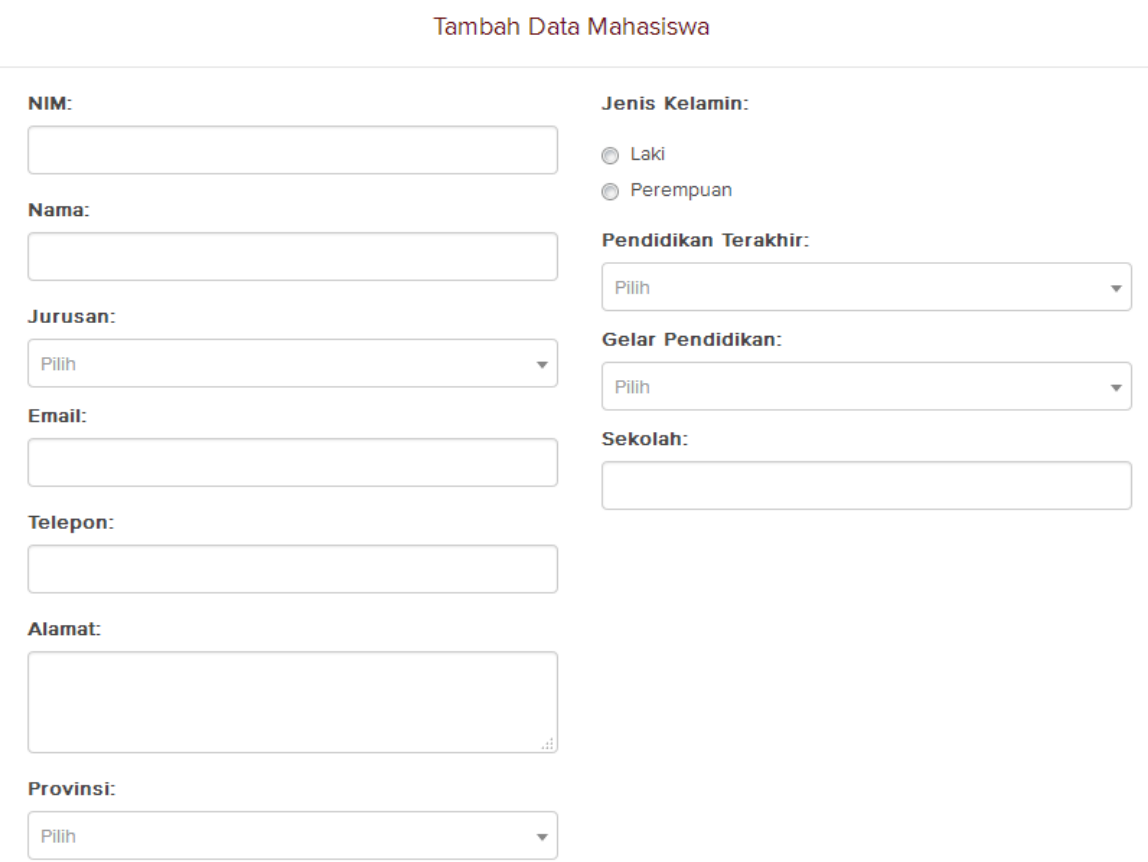

Gambar 10. Halaman Tambah Data Mahasiswa

4. Halaman Data Kelompok Wawancara

Pada Gambar 11 Halaman Data Kelompok Wawancara terdapat kelompok waktu untuk melakukan wawancara berdasarkan jurusan mahasiswa.

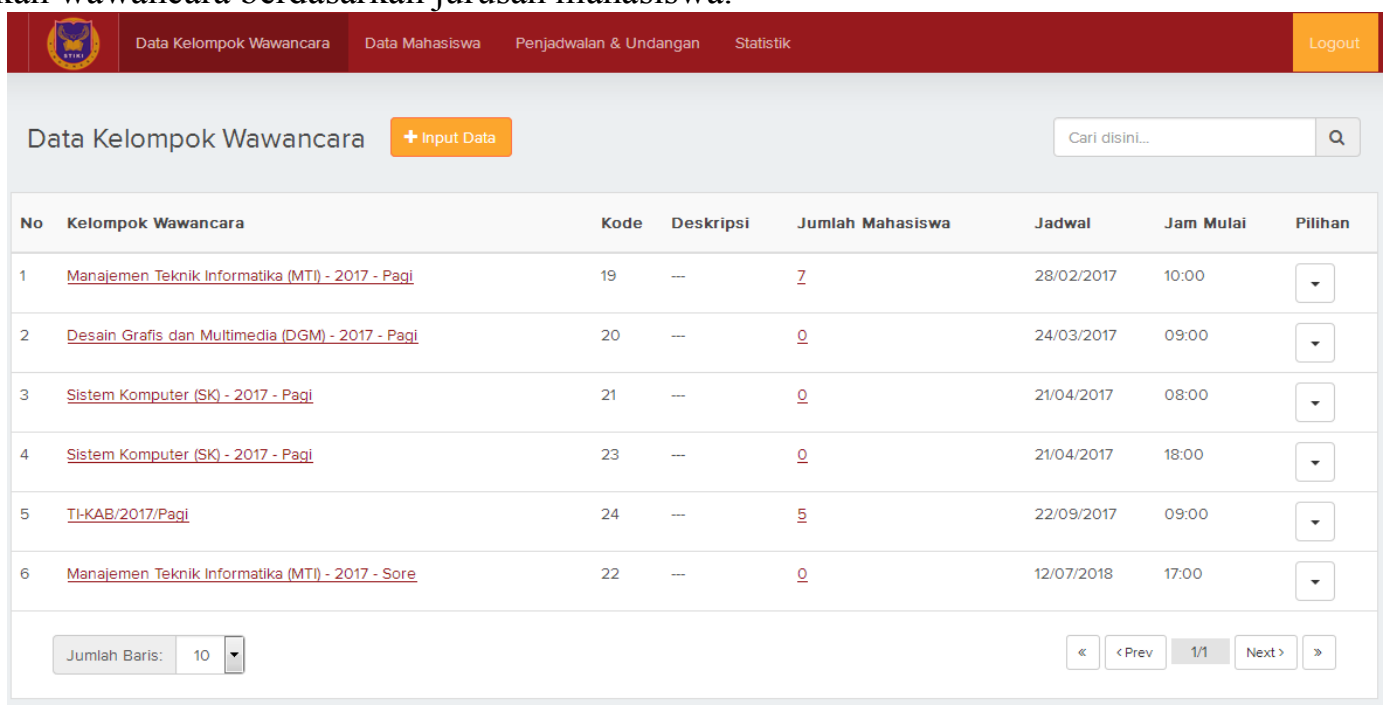

Gambar 11. Halaman Data Kelompok Wawancara

Untuk menginputkan kelompok wawancara yang baru maka dipilih tombol input data, maka form tambah kelompok wawancara akan tampil seperti yang terlihat pada gambar 12. Pada form tambah kelompok wawancara user menginputkan jurusan, angkatan, kelas, deskripsi dan jadwal interview. 
Tambah Kelompok Wawancara

\begin{tabular}{l} 
Jurusan: \\
Deskripsi: \\
Jadwal Interview: \\
Tanggal Otomatis \\
Atur Tanggal \\
\begin{tabular}{llll}
\hline 19/08/2017 Jam Otomatis \\
Jadwal otomatis, 2 minggu dari sekarang!
\end{tabular} \\
\hline
\end{tabular}

\section{Simpan}

Gambar 12. Halaman Tambah Kelompok Wawancara

\section{Halaman Penjadwalan}

Jika data mahasiswa dan kelompok jadwal sudah dimasukkan maka penjadwalan dan undangan dikirim ke masing-masing mahasiswa dengan menekan tombol yang ada pada kolom undang seperti yang terlihat pada gambar13. Setelah mahasiswa di wawancara maka konselor mengisi catatan dan memberikan tanda bintang pada kolom kehadiran.

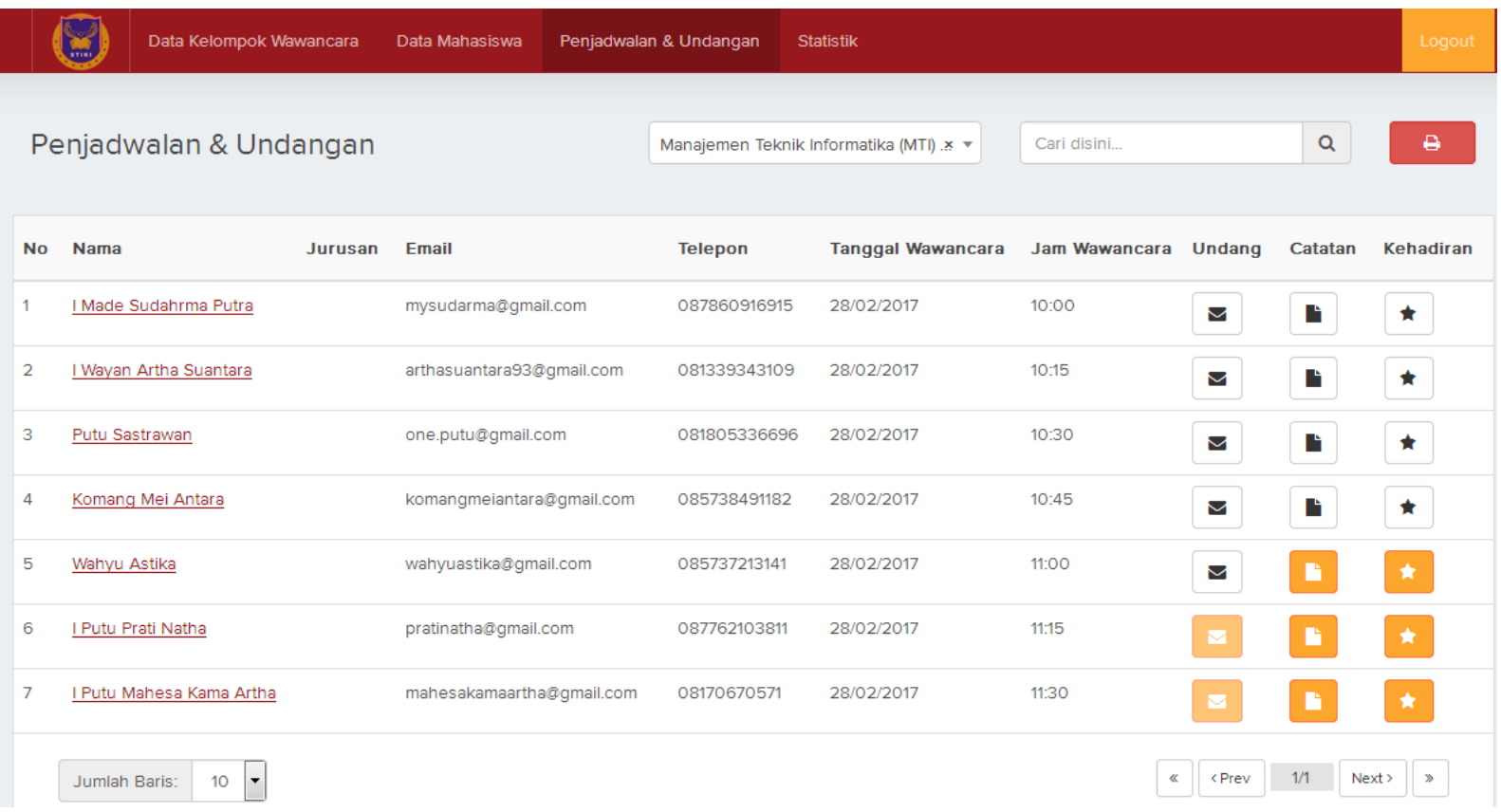

Gambar 13. Halaman Penjadwalan 


\section{B. Pengujian Sistem}

Pengujian sistem menggunakan metode blackbox bertujuan untuk memastikan semua komponen dan fungsi dari sistem telah berjalan sesuai dengan harapan. Adapun hasil dari pengujian sistem menggunakan metode blackbox dapat dilihat pada Tabel 3.

Tabel 4. Hasil Pengujian Sistem

\begin{tabular}{|c|c|c|c|c|c|}
\hline No & Komponen & Skenario Uji & Input & Output Diharapkan & Hasil Pengujian \\
\hline 1 & Validasi Login & $\begin{array}{l}\text { Masukkan } \\
\text { username dan } \\
\text { password yang } \\
\text { benar }\end{array}$ & $\begin{array}{l}\text { Username }= \\
\text { admin } \\
\text { Password }= \\
\text { admin }\end{array}$ & $\begin{array}{l}\text { Masuk ke Menu } \\
\text { Utama }\end{array}$ & Halaman Home \\
\hline 2 & Validasi Login & $\begin{array}{l}\text { Masukkan } \\
\text { username dan } \\
\text { password yang } \\
\text { salah }\end{array}$ & $\begin{array}{l}\text { Username }= \\
\text { admin } \\
\text { Password }= \\
\text { admin } 123\end{array}$ & $\begin{array}{l}\text { Gagal login dan } \\
\text { kursor kembali ke } \\
\text { username }\end{array}$ & $\begin{array}{l}\text { Gagal login dan } \\
\text { masuk ke Menu } \\
\text { Login lagi }\end{array}$ \\
\hline \multirow[t]{2}{*}{3} & \multirow[t]{2}{*}{$\begin{array}{l}\text { Pengelolaan } \\
\text { data } \\
\text { Mahasiswa }\end{array}$} & $\begin{array}{l}\text { Konselor } \\
\text { memasukkan } \\
\text { data Mahasiswa }\end{array}$ & $\begin{array}{l}\text { Data } \\
\text { Mahasiswa }\end{array}$ & $\begin{array}{l}\text { Data dapat ditambah } \\
\text { dan tersimpan ke } \\
\text { dalam tabel }\end{array}$ & $\begin{array}{l}\text { Data dapat ditambah } \\
\text { dan tersimpan ke } \\
\text { dalam tabel. }\end{array}$ \\
\hline & & $\begin{array}{l}\text { Konselor } \\
\text { merubah data } \\
\text { Mahasiswa }\end{array}$ & $\begin{array}{l}\text { Perubahan } \\
\text { Data } \\
\text { Mahasiswa }\end{array}$ & $\begin{array}{l}\text { Data Mahasiswa } \\
\text { dapat dirubah sesuai } \\
\text { inputan dari user }\end{array}$ & $\begin{array}{l}\text { Data Mahasiswa } \\
\text { dapat dirubah dan } \\
\text { tersimpan dalam } \\
\text { tabel. }\end{array}$ \\
\hline \multirow[t]{2}{*}{4} & \multirow[t]{2}{*}{$\begin{array}{l}\text { Pengelolaan } \\
\text { Data } \\
\text { Kelompok } \\
\text { Wawancara }\end{array}$} & $\begin{array}{l}\text { Konselor } \\
\text { memasukkan } \\
\text { data kelompok } \\
\text { wawancara }\end{array}$ & $\begin{array}{l}\text { Data } \\
\text { kelompok } \\
\text { wawancara }\end{array}$ & $\begin{array}{l}\text { Data dapat ditambah } \\
\text { dan tersimpan ke } \\
\text { dalam tabel }\end{array}$ & $\begin{array}{l}\text { Data dapat ditambah } \\
\text { dan tersimpan ke } \\
\text { dalam tabel. }\end{array}$ \\
\hline & & $\begin{array}{l}\text { Konselor } \\
\text { merubah data } \\
\text { kelompok } \\
\text { wawancara }\end{array}$ & $\begin{array}{l}\text { Perubahan } \\
\text { Data } \\
\text { kelompok } \\
\text { wawancara }\end{array}$ & $\begin{array}{l}\text { Data kelompok } \\
\text { wawancara dapat } \\
\text { dirubah sesuai } \\
\text { inputan dari user }\end{array}$ & $\begin{array}{l}\text { Data kelompok } \\
\text { wawancara dapat } \\
\text { dirubah dan } \\
\text { tersimpan dalam } \\
\text { tabel. }\end{array}$ \\
\hline \multirow[t]{2}{*}{5} & \multirow[t]{2}{*}{$\begin{array}{l}\text { Pengelolaan } \\
\text { data Konselor } \\
\text { dan Admin }\end{array}$} & $\begin{array}{l}\text { Admin } \\
\text { memasukkan } \\
\text { data konselor } \\
\text { atau admin } \\
\end{array}$ & $\begin{array}{l}\text { Data Konselor } \\
\text { atau admin }\end{array}$ & $\begin{array}{l}\text { Data dapat ditambah } \\
\text { dan tersimpan ke } \\
\text { dalam tabel }\end{array}$ & $\begin{array}{l}\text { Data konselor atau } \\
\text { admin dapat } \\
\text { ditambah dan } \\
\text { tersimpan di table }\end{array}$ \\
\hline & & $\begin{array}{l}\text { Admin merubah } \\
\text { data konselor } \\
\text { atau admin }\end{array}$ & $\begin{array}{l}\text { Perubahan } \\
\text { data konselor } \\
\text { atau admin }\end{array}$ & $\begin{array}{l}\text { Data konselor atau } \\
\text { admin dapat dirubah } \\
\text { sesuai inputan dari } \\
\text { user }\end{array}$ & $\begin{array}{l}\text { Data konselor dapat } \\
\text { dirubah dan } \\
\text { tersimpan dalam } \\
\text { tabel. }\end{array}$ \\
\hline \multirow[t]{2}{*}{6} & \multirow[t]{2}{*}{$\begin{array}{l}\text { Pengelolaan } \\
\text { Penjadwalan }\end{array}$} & $\begin{array}{l}\text { Konselor } \\
\text { memasukkan } \\
\text { data jadwal }\end{array}$ & Data Jadwal & $\begin{array}{l}\text { Data dapat ditambah } \\
\text { dan tersimpan ke } \\
\text { dalam tabel }\end{array}$ & $\begin{array}{l}\text { Data dapat ditambah } \\
\text { dan tersimpan ke } \\
\text { dalam tabel. }\end{array}$ \\
\hline & & $\begin{array}{l}\text { Konselor } \\
\text { merubah data } \\
\text { jadwal }\end{array}$ & $\begin{array}{l}\text { Perubahan } \\
\text { data jadwal } \\
\text { wawancara }\end{array}$ & $\begin{array}{l}\text { Data jadwal } \\
\text { wawancara dapat } \\
\text { dirubah sesuai } \\
\text { inputan dari user }\end{array}$ & $\begin{array}{l}\text { Data jadwal } \\
\text { wawancara dapat } \\
\text { dirubah dan } \\
\text { tersimpan dalam } \\
\text { tabel. }\end{array}$ \\
\hline 7. & $\begin{array}{l}\text { Pengelolaan } \\
\text { data hasil } \\
\text { wawancara }\end{array}$ & $\begin{array}{l}\text { Konselor } \\
\text { memasukkan } \\
\text { data hasil } \\
\text { wawancara }\end{array}$ & $\begin{array}{l}\text { Penginputan } \\
\text { hasil } \\
\text { wawancara }\end{array}$ & $\begin{array}{l}\text { Data hasil } \\
\text { wawancara } \\
\text { tersimpan }\end{array}$ & $\begin{array}{l}\text { Data hasil } \\
\text { wawancara } \\
\text { tersimpan }\end{array}$ \\
\hline
\end{tabular}




\section{KESIMPULAN DAN SARAN}

\section{Kesimpulan}

Dalam perancangan dan pengembangan sistem informasi penjadwalan wawancara mahasiswa baru pada STMIK STIKOM Indonesia berbasis web, dapat disimpulkan beberapa hal sebagai berikut.

1. Perancangan dan pengembangan sistem informasi penjadwalan wawancara mahasiswa baru pada STMIK STIKOM Indonesia dibuat berdasarkan hasil wawancara. Dari data-data tersebut didapatkan beberapa requirement atau kebutuhan sistem yang digunakan dalam pembuatan pengembangan sistem dan dilanjutkan dengan analisa data, perancangan sistem, pembangunan sistem dan yang terakhir adalah pengujian sistem.

2. Pemanfaatan Sistem Informasi Penjadwalan Mahasiswa Baru berbasis Web memberikan kemudahan bagian konselor dalam melakukan penjadwalan dan mengolah data penjadwalan wawancara kerja dari manapun sehingga tidak harus pada tempat tertentu.

3. Dengan menerapkan metode FIFO (First In First Out) pada Sistem Informasi Penjadwalan Mahasiswa Baru sangat membantu karena secara otomatis mahasiswa yang terlebih dahulu mendaftar, maka akan otomatis dibuatkan jadwal wawancara duluan sehingga mahasiswa baru tidak akan kecewa.

4. Berdasarkan hasil pengujian yang telah dilakukan dapat disimpulkan keseluruhan fungsi dari sistem dapat berjalan dengan lancar.

5. Dengan adanya Sistem Informasi Penjadwalan Mahasiswa Baru ini, sangat membantu STMIK STIKOM Indonesia dalam proses wawancara yang dilakukan oleh bagian konselor.

\section{Saran}

Saran yang dapat direkomendasikan dalam pengembangan sistem informasi penjadwalan wawancara mahasiswa baru pada kampus STMIK STIKOM Indonesia berbasis web ini ke depannya antara lain.

1. Penambahan fitur tes potensi akademik dan tes kepribadian agar dapat mengelompokkan dan mengetahui mahasiswa yang membutuhkan perhatian yang lebih selama kuliah di kampus STMIK STIKOM Indonesia

2. Penambahan fitur statistik berdasarkan waktu (tahun, bulan, minggu, dan hari)

\section{DAFTAR RUJUKAN}

Al Fatta, Hanif. 2007. Analisis dan Perancangan Sistem Informasi. Yogyakarta: ANDI. Herjanto, Eddy. 2007 Manajemen Operasi, Edisi Ke-3. Jakarta: Gramedia Widiasana Indonesia. Haryanto, Edy Victor.2012. Sistem Operasi Konsep dan Teori. Yogyakarta: Penerbit ANDI. Jogiyanto HM. 2005.Analisis \& Desain: Sistem Informasi Pendekatan Terstruktur Teori dan Praktik Aplikasi Bisnis. Yogyakarta: ANDI

Kusrini.2007.Strategi Perancangan dan Pengelolaan Basis Data. Yogyakarta: ANDI

Pressman, Roger. S. 2002. Rekayasa Perangkat Lunak Pendekatan Praktisi (Buku 1). ANDI: Yogyakarta

Simarmata, Janner. 2007. Perancangan Basis Data. Yogyakarta: ANDI 